SECTION 9. Chemistry and chemical technology.

\author{
Alla Georgievna Yaschenko \\ master student, \\ Tambov state technical University, Russia \\ yashenkoalla@mail.ru \\ Natalija Vjacheslavovna Orlova \\ PHD, associate Professor, \\ Tambov state technical University, Russia \\ Natal'ja Viktorovna Pjatakova \\ student, \\ Tambov state technical University, Russia
}

\title{
THE RESEARCH OF THE CRYSTALLIZATION PROCESS OF SULFAMIC ACID
}

Abstract: Was conducted investigation of crystallization process of sulfamic acid. Was defined the influence of the main technological parameters of stage on the qualitative characteristics of sulfamic acid. Were selected the optimum process conditions, taking into account the yield of the desired product and its compliance with the technical conditions.

Key words: crystallization, sulfamic acid, bulk density, flowability, particle size distribution, mass fraction of the basic substance, yield of target product.

\section{УДК 66.963}

\section{ИССЛЕДОВАНИЕ ПРОЦЕССА КРИСТАЛЛИЗАЦИИ СУЛЬФАМИНОВОЙ КИСЛОТЫ}

Аннотация: Проведено исследование процесса кристаллизации сульфаминовой кислоты. Определено влияние основных технологических параметров стадии на качественные характеристики сульфаминовой кислоты. Выбран оптимальный режим прочесса, учитывающий выход иелевого продукта и соответствие его техническим условиям.

Ключевые слова: кристаллизация, сульфаминовая кислота, насыпная плотность, сыпучесть, гранулометрический состав, массовая доля основного вещества, выход ичелевого продукта.

На данный момент сектор бытовой химии в России имеет хорошие перспективы. Уровень потребления различных товаров этого сегмента (чистящих и моющих средств, стиральных порошков и т.п.) на душу населения значительно ниже, чем в Европе и США, но он постоянно растет. Изменяется и расширяется ассортимент, производители дополняют товарный ряд продуктами разных ценовых категорий [1].

Сульфаминовая кислота получила широкое применение в промышленности, а именно:

- в производстве синтетических моющих средств;

- очистка промышленной аппаратуры от минеральных отложений, молочного и пивного камня;

- удаление карбонатных отложений (накипи) с теплообменной аппаратуры, радиаторов, бытовой посуды;

- производство огнестойких материалов и гербицидов; 
- обработка призабойной зоны нефтяных скважин с целью увеличения нефтеотдачи пласта $[1,2]$.

Во всех областях применения сульфаминовой кислоты предъявляется ряд жестких требований, касающихся гранулометрического состава, насыпной плотности, сыпучести, физико-химических свойств, транспортировки и хранения готового продукта. Готовый продукт должен соответствовать следующим параметрам: концентрация целевого вещества не менее 99,5 \%; массовая доля сульфат - ионов до 0,04\%; содержание нерастворимых в

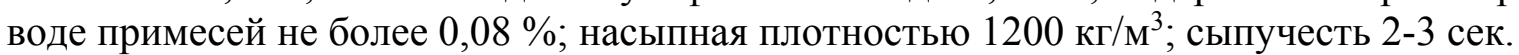

На базе применяемой технологии (сульфирование мочевины $\rightarrow$ выделение $\rightarrow$ кристаллизация $\rightarrow$ фильтрация $\rightarrow$ сушка) необходимо совершенствование стадии кристаллизации, которая является основополагающей для формирования качества товарного продукта [3-4].

Кристаллизация является одним из наиболее эффективных методов получения веществ в чистом виде. Степень чистоты получаемого продукта при этом зависит как от условий проведения процесса кристаллизации и последующих вспомогательных операций (фильтрации, промывки), так и характера примесей, присутствующих в растворе [5].

Стадия кристаллизации играет определяющую роль в формировании качественных характеристик сульфаминовой кислоты: полнота извлечения целевого вещества и формирование кристаллической структуры зависят от начальной и конечной температуры процесса перекристаллизации [6-8].

Ранее, в работах [9-10], рассматривалось влияние скорости охлаждения и температурного режима процесса кристаллизации на гранулометрический состав сульфаминовой кислоты и её насыпную плотность. Однако в этих исследованиях не были учтены такие показатели как массовая доля основного вещества и примесей, сыпучесть и выход целевого продукта.

При определении оптимального температурного режима, оказывающего существенное влияние на содержание основного вещества и примесей в кристаллах сульфаминовой кислоты и на выход целевого продукта, использовали лабораторную установку, состоящую из термостата с термометром, привода с частотным регулятором, емкости со змеевиком и перемешивающим устройством.

В емкость заливается дистиллированная вода и, подачей горячей воды в змеевик, нагревается до необходимой температуры. По достижению заданной температуры загружается навеска, суспензия выдерживается при заданной температуре до полного растворения кислоты.

Чтобы избежать возникновения большого числа центров кристаллизации охлаждающую воду в змеевик подавали после выдержки в течение 30 минут, а затем охлаждали до конечной температуры $15{ }^{0} \mathrm{C}$. Полученная суспензия сульфаминовой кислоты фильтруется на воронке Бюхнера. Кристаллы сушатся в сушильном шкафу при температуре $75^{\circ} \mathrm{C} 24$ часа.

При проведении эксперимента определяли влияние температурного режима на захват примесей кристаллами сульфаминовой кислоты. Так смещение начальной температуры кристаллизации в область более высоких значений и смещение конечной температуры выделения в область более низких значений приводит к определенному уменьшению содержания примесей (с $0,58 \%$ до $0,06 \%$ ). Установлено также, что наименьшее протекание гидролиза происходит при температуре выделения $20^{\circ} \mathrm{C}$ - от 0,3 до 0,6\%. При повышении температуры выделения потери продукта за счет гидролиза составляют от 1,5 до 3\%. Таким образом, снижение температуры выделения до $20^{\circ} \mathrm{C}$ может привести к увеличению выхода продукта на 1,8-2,3\%.

В сводной таблице (табл. 1) представлены результаты исследований, с учетом данных работ $[9,10]$. 
Качественные показатели сульфаминовой кислоты

Таблица 1

\begin{tabular}{|l|c|c|c|}
\hline \multirow{2}{*}{\multicolumn{1}{|c|}{ Показатель }} & \multicolumn{3}{|c|}{ Температурный интервал кристаллизации } \\
\cline { 2 - 4 } & $\mathbf{6 0}^{\mathbf{0}} \mathbf{C}-\mathbf{2 0}^{\mathbf{0}} \mathbf{C}$ & $\mathbf{7 0}^{\mathbf{0}} \mathbf{C}-\mathbf{2 0}^{\mathbf{0}} \mathbf{C}$ & $\mathbf{8 0}^{\mathbf{0}} \mathbf{C}-\mathbf{2 0}^{\mathbf{0}} \mathbf{C}$ \\
\hline Массовая доля САК, \% & 98,4 & 99,1 & 99,5 \\
\hline Массовая доля примесей, \% & 0,58 & 0,32 & 0,06 \\
\hline Насыпная плотность, кг м $^{3}$ & 1127,13 & 1140,79 & 1158,52 \\
\hline Сыпучесть, с & $3-3,5$ & $4-4,5$ & $4-5,5$ \\
\hline Выход целевого продукта, \% & 87,4 & 90,6 & 95,8 \\
\hline
\end{tabular}

Анализ полученных данных позволяет сделать вывод о том, что оптимальный температурный интервал кристаллизации, при котором полученный продукт имеет

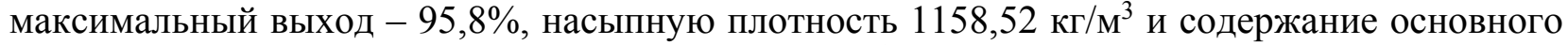
вещества 99,5\%, находится в пределах $80-20^{\circ} \mathrm{C}$. Стоит также учесть, что не один рассмотренный нами режим кристаллизации не обеспечивает требуемую сыпучесть продукта, поэтому в дальнейших работах следует обратить внимание именно на этот параметр.

\section{References:}

1. Оптические отбеливатели и сульфаминовая кислота ОАО «Пигмент» для товаров бытовой химии. URL: http://www.krata.ru/the-news/164--lr-.html (Дата доступа 14.07.2014).

2. Гиматудинов, Ш.К. Справочная книга по добыче нефти / Ш.К. Гиматудинов - М.: Книга по Требованию, 2012. - 456 с.

3. Бэмфорт, А.В. Промышленная кристаллизация: учеб. / А.В. Бэмфорт. - М.: Химия, 1969. - 239c.

4. Хамский, Е.В. Кристаллизация в химической промышленности. / Е.В. Хамский - М.: Химия, 1986. - 343с.

5. Лебедев, И.В. Кристаллизация из растворов в химической промышленности. / И.В. Лебедев, М.И. Эльцуфен, В.В. Коган. - М.: Химия, 1986. - 304с.

6. Матусевич, Л.Н. Кристаллизация из растворов в химической промышленности. / Л.Н. Матусевич. - М.: Химия, 1968. - 304c.

7. Гельперин, Н.И. Основы техники фракционной кристаллизации. / Н.И. Гельперин, Г.А. Носов. - М.: Химия, 1986. - 303с.

8. Тодес, О.М. Массовая кристаллизация из растворов. / О.М. Тодес, В.А. Себалло, А.Д. Гольцикер. - Л.: Химия, 1984. - 231 с.

9. Ященко, А.Г. Влияние скорости охлаждения на процесс массовой кристаллизации сульфаминовой кислоты / А.Г. Ященко, Д.Ю. Федоров, Н.С. Сорокина // Интеллектуальный потенциал XXI века: ступени познания: Сборник материалов XXI Молодежной международной научно-практической конференции / Под общ. ред. С.С. Чернова. - Новосибирск: Издательство ЦРНС, 2014. - С.167-172.

10. Ященко А.Г. Исследование технологии получения и качественных характеристик сульфаминовой кислоты / А.Г. Ященко // Проблемы техногенной безопасности и устойчивого развития [Электронный ресурс]: сб. науч. ст. молодых ученых, аспирантов и студентов / ФГБОУ ВПО "ТГТУ". - Тамбов: Изд-во ФГБОУ ВПО "ТГТУ", 2014. Вып. V. - С.197-201. 